\title{
A VIABILIDADE DOS CUSTOS DE UTILIZAÇÃO DA VINHAÇA NO CULTIVO DE CANA- DE-AÇÚCAR
}

Stephanie Funari Amaral Gusmão, Sonia Sanae Sato, Suzana Chiari Bertolli

Universidade do Oeste Paulista - UNOESTE, MBA em Finanças e Controladoria, Presidente Prudente, SP. E-mail: stephaniefagusmao@gmail.com

\section{RESUMO}

A cana-de-açúcar esbarra em diversas questões ecológicas, dentre elas a produção de resíduos. A vinhaça é um resíduo proveniente da destilação do vinho para a obtenção do álcool e pode ser utilizada como fertilizante em áreas de produção de cana-de-açúcar. O objetivo deste estudo foi analisar a viabilidade dos custos de utilização da vinhaça no cultivo da cana-de-açúcar de uma agroindústria localizada no Pontal do Paranapanema/SP. A metodologia constou de referências bibliográficas, pesquisa qualitativa, descritiva, além de ser realizado um estudo de caso. Os resultados foram de forma positiva, pois o custo de aplicação da vinhaça é viável para a agroindústria. Foi possível concluir que se a vinhaça for utilizada na fertirrigação de maneira correta, ela aumenta a produtividade do canavial e diminui os custos gerados com fertilizantes.

Palavras-chave: Cana-de-açúcar. Vinhaça. Gestão de custos. Agroindústria.

\section{THE FEASIBILITY OF THE COSTS OF VINASSE USE IN THE SUGARCANE CULTIVATION}

\begin{abstract}
The sugarcane comes up against several ecological issues, among them the production of waste. Vinasse is a residue from the distillation of wine to obtain the alcohol and can be used as fertilizer in areas of sugarcane production. The objective of this study was to analyze the viability of vinhaça utilization costs in sugarcane cultivation of an agroindustry located in Pontal do Paranapanema/ SP. The methodology consisted of bibliographical references, qualitative, descriptive research, in addition to conducting a case study. The results were positive, because the cost of applying the vinasse is feasible for the agroindustry. It was possible to conclude that if the vinasse is used in the fertirrigation correctly, it increases the productivity of the cane field and reduces the costs generated with fertilizers.
\end{abstract}

Keywords: Sugarcane. Vinasse. Costs management. Agroindustry.

\section{INTRODUÇÃO}

Como a preocupação com a preservação do meio ambiente aumenta a cada dia, e com isso os esforços para a obtenção de estratégias de desenvolvimento sustentável, isto tem conduzido diversos ramos de conhecimento para o desenvolvimento de novas especialidades que estejam voltadas para estes fins (CALLADO, A.A.; CALLADO, A.L., 2007).

Neste contexto, a expansão da cultura da cana-de-açúcar esbarra em diversas questões ecológicas, dentre elas a produção de resíduos como a vinhaça. A vinhaça é um resíduo líquido proveniente da destilação do vinho para a obtenção do álcool. Produzida à razão de, aproximadamente, 13 litros por litro de etanol, constitui o mais importante efluente líquido da agroindústria da cana (BRAUNBECK; ALBRECHT NETO, 2009; VEIGA FILHO; SZMRECSÁNYI; RAMOS, 
2010). A vinhaça, anteriormente era considerada um resíduo, mas hoje em dia pode ser vista como um subproduto que possui a função de fertilizante.

No entanto, durante décadas, a vinhaça foi descartada indevidamente sobre recursos hídricos e/ou áreas de sacrifício, nas proximidades das usinas, provocando grande poluição e mortandade de peixes, dada a sua elevada Demanda Bioquímica de Oxigênio (DBO), além de ocasionar eutrofização pelo excesso de nutrientes e incomodo às populações vizinhas provocadas pelo seu característico mau cheiro (VEIGA FILHO; SZMRECSÁNYI; RAMOS, 2010). Mas, essa prática não é mais utilizada, pois hoje em dia a vinhaça é destinada para a fertilização no canavial.

Assim, apesar dos potenciais impactos que a indústria da cana-de-açúcar pode causar ao meio ambiente, todos os resíduos da sua cadeia produtiva podem ser reutilizados no próprio processo produtivo, o que faz o setor canavieiro um exemplo a ser seguido no quesito gerenciamento ambiental (ROSSETO, 2010).

A vinhaça, comumente é utilizada em substituição à adubação potássica e parte do nitrogênio necessário para a cultura da cana-de-açúcar, sendo que a dosagem utilizada é calculada de acordo com a base no teor de potássio ambientalmente adequado de acordo com a Companhia Ambiental do Estado de São Paulo (CETESB, Normativa 4.231). Estudos apontam que com a aplicação da vinhaça a produtividade de cana-de-açúcar pode aumentar de 5 a $10 \%$ em comparação às áreas sem aplicação podendo, portanto, influenciar positivamente os ganhos financeiros da agroindústria (SANTOS; BORÉM; CALDAS, 2012).

Por outro lado, a reutilização da vinhaça como adubo orgânico em áreas de longa distância de produção de cana-de-açúcar, podem gerar custos para a empresa, como, por exemplo, a mecanização, a construção de canais e tubulação, as compras de caminhões, combustível, recursos humanos, entre outras (CALLADO, A.A.; CALLADO, A.L., 2007). Nesse sentido, a gestão de custos assume papel de grande relevância, pois representa a possibilidade de significativa racionalização nos processos de produção, otimizando os recursos e proporcionando melhores resultados (SANTOS; BORÉM; CALDAS, 2012, p. 620).

Dessa maneira, sabe-se que os custos são consequência natural da produção e que a indústria bem gerenciada tem como objetivo, a busca de métodos de produção com o mínimo custo, ou seja, a otimização de processos. Custo é todo gasto envolvido direta ou indiretamente com a produção, sem o qual ela não poderia acontecer, além de, toda despesa para deixar o produto pronto para a venda e com isso sejam obtidos os produtos finais (SANTOS; BORÉM; CALDAS, 2012).

Diante disso, é realizado o aprofundamento do estudo desta pesquisa, considerando que a gestão de custos poderá impulsionar o conhecimento da administração da agroindústria, e com isso minimizar a expansão de novas áreas de cultivo, pois se a vinhaça aumenta a produtividade, também gera informações básicas para otimizar a eficiência dos custos, e ainda diminui o impacto ambiental.

Portanto, o objetivo dessa pesquisa foi analisar a viabilidade dos custos de utilização da vinhaça no cultivo da cana-de-açúcar de uma agroindústria localizada no Pontal do Paranapanema/SP.

\section{METODOLOGIA}

A abordagem metodológica deriva essencialmente da proposta que o artigo pretende desempenhar, diante disso na presente pesquisa foi realizada uma pesquisa bibliográfica, feita por meio de livros e artigos específicos de autores conceituados sobre o tema, utilizando a fontes secundárias. Além disso, é considerada uma pesquisa qualitativa e descritiva. E também foi realizado um estudo de caso com dados coletados da agroindústria por meio de um representante 
da mesma, localizada no Pontal do Paranapanema/SP, e o objeto de estudo foi à viabilidade da vinhaça.

\section{RESULTADOS}

Os dados coletados sobre a empresa em relação à viabilidade da vinhaça foi realizado por meio de um dos representantes da agroindústria, no mês de junho de 2017, e se baseia na viabilidade dos custos de aplicação da vinhaça. De acordo com dados da agroindústria analisada, a mesma possui um programa de gestão de resíduos industriais focado na utilização da vinhaça e toda vinhaça gerada é utilizada na fertirrigação dos canaviais.

Ademais, a vinhaça contribui para o aumento da produtividade, mas para que isso aconteça ela precisa atender o Plano de Aplicação da Vinhaça (PAV), que determina as taxas de aplicação por tipo de solo e análises realizadas no mesmo, e também se houver a retirada da enorme quantidade de água que contém na vinhaça, por volta de $93 \%$, o que melhora a concentração da mesma e consequentemente um melhor desempenho na adubação, mas não é possível descrever a porcentagem exata, pois varia de empresa para empresa.

Em relação às desvantagens da vinhaça, só ocorre se a aplicação não seguir as recomendações descritas acima, já às vantagens são várias, como diminuir os custos com outros fertilizantes, ganho na produtividade e também não há necessidade de utilizar água para a irrigação, já que quase toda sua composição é de água.

E ao falar dos custos gerados para aplicação de vinhaça, eles são vantajosos, e a agroindústria não enxerga como custo, mas sim como ganho, já que é a vinhaça é produzida por meio do processo de fabricação de açúcar e etanol. E hoje em dia existem vários meios para baratear o transporte desse fertilizante, como por meio de adutoras, a concentração da mesma, diminuindo os custos de aplicação e por substituir alguns fertilizantes e a água. Então, caso a vinhaça não existisse deveriam ser utilizados outros produtos o que elevaria ainda mais os custos da produção, já que a vinhaça é um resíduo e não há custo para a sua produção.

\section{DISCUSSÃO}

Atualmente, o Brasil é o maior produtor da cultura de cana-de-açúcar, contribuindo com $40 \%$ da produção mundial. A produção total de cana-de-açúcar moída na safra 2014/2015 é estimada em 642,1 milhões de toneladas, queda de $2,5 \%$ em relação ao volume colhido na safra anterior (CONAB, 2014). O crescimento da cultura da cana-de-açúcar, diante da demanda global por energia renovável, provoca preocupações quanto à sua sustentabilidade. Nesse sentido, práticas de reincorporação de resíduos e efluentes, especialmente a vinhaça, têm permitido que a agroindústria atinja tal situação (MUTTON et al. 2009).

A vinhaça é um subproduto da agroindústria, resíduo final da destilação do vinho de fermentação para a obtenção do etanol, possui uma coloração parda e quando é exposta ao ar, escurece. Ela é o mais preocupante e mais importante líquido da agroindústria sucro-energética. Praticamente toda a vinhaça produzida no Brasil é aplicada em áreas de cultivo de cana-de-açúcar para atender às exigências nutricionais, principalmente de potássio (SANTOS; COLODETTE; QUEIROZ, 2013).

Apesar de a aplicação ser realizada de forma controlada segundo estabelecido pela CETESB, ainda se discute que a aplicação continuada da vinhaça, por vários anos seguidos, mesmo em doses baixas, pode gerar a saturação de cátions, principalmente de Potássio (K) no Centro de Tecnologia Canavieira (CTC) dos solos, ocasionando problemas de lixiviação da sua composição para as águas subterrâneas. 
É sabido que a biodigestão ou fermentação anaeróbica é um método de reciclagem que consiste na produção de gás combustível e também de adubos, a partir de compostos orgânicos. Portanto, no caso da vinhaça, a biodigestão pode processar a carga orgânica dela, gerando o biogás, que pode ser aproveitado para geração de energia elétrica, e a vinhaça biodigerida ainda mantém seu poder fertilizante e pode ser utilizada no canavial (LUZ et. al.,2010).

Já, a concentração da vinhaça tem como objetivo a extração do excesso de água sem perda do material sólido dissolvido. Este processo resulta em uma considerável redução do volume de vinhaça sendo uma opção para reduzir os custos com o transporte terrestre, mas o processo de evaporação consome grande quantidade de energia (SILVA, 2012). Sendo que, esta energia pode ser produzida pela prévia biodigestão da própria vinhaça. O biogás, por exemplo, produto da biodigestão, pode ser utilizado como fonte de energia para posterior concentração da vinhaça, originando o Concentrado de Vinhaça Biodigerida (CVB). Sabe-se que tanto a biodigestão quanto a concentração alteram a composição da vinhaça e dessa maneira, reduz o conteúdo de matéria orgânica (SILVA, 2012) e com isso diminui os custos gerados para o seu transporte.

De forma geral, no sistema sucroalcooleiro recomendam-se dois sistemas de custeio: o sistema tradicional e o sistema direto, o primeiro atende a legislação fiscal e deve ser utilizado para realizar apenas os registros contábeis. Já o sistema de custeio direto, que também pode ser denominado de variável ou marginal, é o mais utilizado por quem responde pela parte administrativa nas agroindústrias, pois possibilita embasar decisões do dia a dia como, por exemplo, o custo gerado na produção (SANTOS; BORÉM; CALDAS, 2012). Ademais, o sistema tradicional pode acarretar informações defasadas no processo decisório da administração da empresa.

Ainda sobre o setor sucroalcooleiro, alguns estudos permitem estimar os custos de aplicação de vinhaça nos procedimentos de fertirrigação como, por exemplo, no transporte por canais de aspersão. Os gastos com tubulações e aplicação de vinhaça por irrigador de carretel geram um custo próximo a $\mathrm{R} \$ 2,35$ por $\mathrm{m}^{3}$ de vinhaça. Enquanto que por transporte em caminhãotanque e a aplicação por irrigação de carretel, os gastos são próximos a $\mathrm{R} \$ 2,83$ por $\mathrm{m}^{3}$ de vinhaça. Um exemplo é a concentração de vinhaça a 40 Brix, sendo que o Brix pode variar de $15 \%$ a $65 \%$, gera o custo de $\mathrm{R} \$ 67,00$ por $\mathrm{m}^{3}$ de vinhaça, enquanto que o transporte da vinhaça e aplicação por caminhão-tanque distribuidor pode gerar o custo no valor de $\mathrm{R} \$ 69,59$ por $\mathrm{m}^{3}$ de vinhaça (SANTOS; BORÉM; CALDAS, 2012). Sendo assim, o Brix é uma escala numérica que determina a quantidade de compostos solúveis na sacarose e é recomendada para o corte da cana-de-açúcar, aquela que possui um Brix igual ou superior que 18‥ Já no exemplo acima, quando o Brix está a 40 é no caso da vinhaça já estar concentrada.

\section{CONCLUSÃO}

A pesquisa foi baseada nos custos da utilização da vinhaça, tendo como foco a viabilidade para a agroindústria, verificando então, se há vantagens financeiras na utilização da vinhaça, pois é sabido que vantagens ambientais existem, como por exemplo, a sua utilização como fertilizante no canavial e com isso não necessita da utilização da água, pois a maior parte de sua composição é feita de água.

Atualmente há vários meios para se depreciar o transporte desse fertilizante, a vinhaça, como por meio de adutoras, concentrando a mesma, ou seja, a vinhaça concentrada, o que fará a geração de gastos diminuir, pois ocorrerá a diminuição significativamente da quantidade de vinhaça que será transportada e com isso minimizar seus custos de aplicação.

A partir de dados coletados sobre agroindústria por meio de um representante de uma determinada agroindústria do Pontal do Paranapanema, foi possível verificar que a agroindústria 
não visualiza como um custo, mais sim como um ganho, já que o produto vinhaça é produzido por meio do processo de fabricação de açúcar e etanol, sendo um resíduo e não havendo custo para a sua fabricação.

Portanto, a pesquisa obteve uma resposta positiva sobre a viabilidade dos custos do transporte da vinhaça e sobre o aumento da produtividade com a utilização da vinhaça como fertilizante, não sabendo exatamente quanto aumenta em porcentagem. Mas, como a vinhaça não deve ser utilizada de qualquer maneira, ou seja, não podendo ser descartada de qualquer forma, por causa dos efeitos negativos que ela gera ao meio ambiente, além das multas de crime ambiental que possuem valores exorbitantes, já é um ganho para a empresa, pois ela não gera custo e com isso, economiza com fertilizantes e água.

\section{REFERÊNCIAS BIBLIOGRÁFICAS}

BRAUNBECK, O. A.; ALBRECHT NETO, E. Logística do transporte de matéria-prima e resíduos da cana-de-açúcar. In: CORTEZ, L. A. B. Bioetanol de cana-de-açúcar: P\&D para produtividade e sustentabilidade. Editora Edgard Blücher, São Paulo, SP. 2009, pp. 487-504.

CALLADO, A.A.C.; CALLADO, A.L.C. Índices financeiros ambientais uma proposta conceitual. São Paulo, Gesta; v. 3, n. 4, p. 116-133, out/dez. 2007. Disponível em: <http://www.unisantos.br/mestrado/gestao/egesta/artigos/135.pdf> Acesso em: 10 dez. 2016.

CONAB. Acompanhamento da Safra Brasileira: cana-de-açúcar. Companhia Nacional de Abastecimento. Safra 2014/2015. Brasília. 2014 v.1, n. 3.

VEIGA FILHO, A, A.; SZMRECSÁNYI, T.; RAMOS, P. Impactos da evolução do setor sucroalccoleiro: sumário das questões que balizarão uma evolução sustentável. In: CORTEZ, L. A. B. Bioetanol de cana-de-açúcar: P\&D para produtividade e sustentabilidade. Editora Edgard Blücher, São Paulo, SP. 2010, pp. 279-290.

MUTTON M. G.; ROSSETTO R.; MUTTON M. J. R. Utilização agrícola da vinhaça. In: CORTEZ, L. A. B. Bioetanol de cana-de-açúcar: P\&D para produtividade e sustentabilidade. Editora Edgard Blücher, São Paulo, SP. 2010, pp. 423-440.

SANTOS, F.; COLODETTE, J.; QUEIROZ, J. H. Bioenergia \& biorrefinaria. Cana-de-açúcar \& espécies florestais. 22 ed. Minas gerais: Os editores, 2013.

SANTOS, F.; BORÉM, A.; CALDAS, C. Cana-de-açúcar: Bioenergia, açúcar e etanol: Tecnologias e perspectivas . 2.ed. Viçosa: UFV. 2012.

SILVA J. A.S. Concentrado de vinhaça biodigerida como fertilizante: efeito no substrato, no crescimento e nutrição da cana-de-açúcar. Jaboticabal: Unesp. 2012 Disponível em: <http://repositorio.unesp.br/bitstream/handle/11449/96886/silva_jas_me_jabo.pdf?sequence=1 $>$ Acessado em: 02 de fev. 2017 